\title{
Mechanistic Insights on the Mechanosynthesis of Phenytoin, a WHO Essential Medicine
}

\author{
Francesco Puccetti, ${ }^{[a],[+]}$ Stipe Lukin, ${ }^{[b],\left[{ }^{+}\right]}$Krunoslav Užarević, ${ }^{[b]}$ Evelina Colacino, ${ }^{[c]}$ Ivan Halasz, ${ }^{* b]}$ \\ Carsten Bolm*[a] and José G. Hernández ${ }^{*[b]}$
}

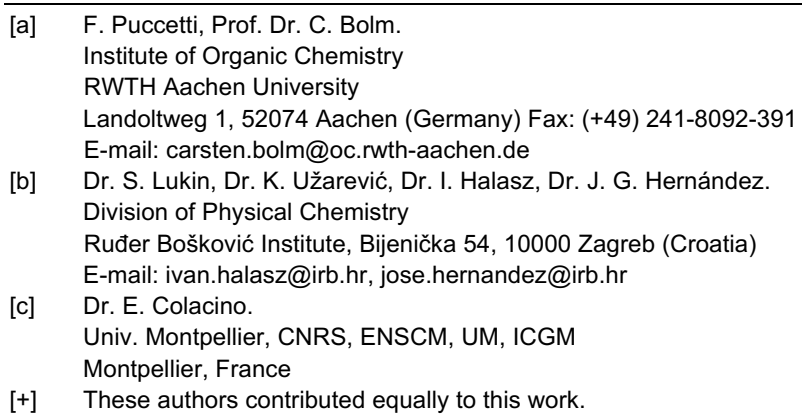

Supporting information for this article is given via a link at the end of the document.

\begin{abstract}
In recent years, mechanochemistry has enriched the toolbox of synthetic chemists, enabling faster and more sustainable access to new materials and existing products, including active pharmaceutical ingredients (APIs). However, molecular-level understanding of most mechanochemical reactions remains limited, delaying the implementation of mechanochemistry in industrial applications. Herein, we have applied in-situ monitoring by Raman spectroscopy to the mechanosynthesis of phenytoin, a World Health Organization (WHO) Essential Medicine, enabling the observation, isolation, and characterization of key molecular-migration intermediates involved in the single-step transformation of benzil, urea, and $\mathrm{KOH}$ into phenytoin. This work contributes to the elucidation of a reaction mechanism that has been subjected to a number of interpretations over time and paints a clear picture of how mechanosynthesis can be applied and optimized for the preparation of added-value molecules.
\end{abstract}

The simplicity, effectiveness and sustainability aspects of mechanochemistry ${ }^{[1]}$ have prompted its implementation for chemical synthesis across several fields of research. ${ }^{[2]}$ Some advantages of mechanosynthesis include complete or partial reduction of waste production, the acceleration of chemical transformations, and the opportunity to induce structural changes unattainable by other activation modes. ${ }^{[3]}$ Applicatively, among the various techniques currently available in mechanosynthesis, ${ }^{[4]}$ ball milling is undoubtedly the most versatile. ${ }^{[4 a, b]}$

Despite all the merits of mechanochemistry, the lack of mechanistic understanding of most mechanochemical transformations is delaying its application as a mainstream methodology for synthesis. ${ }^{[5]}$ A central challenge to study the evolution of chemical reactions in ball mills arises from the use of non-transparent closed milling vessels operated at high speeds, which impedes the monitoring of the reactions using standard methods. However, over the past few years, this obstacle has been partially overcome with the development of in-situ monitoring techniques based on synchrotron powder X-ray diffraction and Raman spectroscopy, ${ }^{[6]}$ which have enabled a

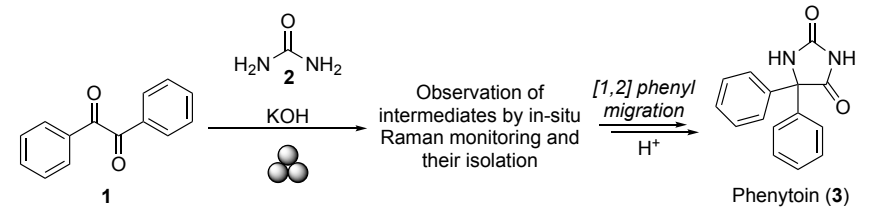

Scheme 1. Mechanosynthesis of phenytoin (3). For mechanochemically activated reactions, the formalism proposed by Hanusa was used..$^{[7]}$

more detailed understanding of mechanochemical reactions by ball milling. For example, we recently studied the mechanochemical iconic benzil-benzilic acid rearrangement, where in-situ monitoring of the reaction by synchrotron X-ray powder diffraction, Raman spectroscopy, and real-time temperature sensing revealed the exact instant of the irreversible $[1,2]$-intramolecular phenyl migration in benzil (1) ${ }^{[8]}$ Unfortunately, however, also this approach had limitations as none of the applied techniques allowed the detection of presumed intermediates before the rearrangement. ${ }^{[9]}$

Phenytoin (3) is a broadly prescribed anticonvulsant drug categorized as an essential medicine by the World Health Organization (WHO). ${ }^{[10,11]}$ The synthesis starts from benzil (1), urea (2), and $\mathrm{KOH}$ (Scheme 1), and, importantly, the reaction path shares mechanistic similarities with the previously studied benzilbenzilic acid rearrangement, ${ }^{[8]}$ namely the involvement of an $[1,2]-$ intramolecular phenyl shift. Although this rearrangement has thoroughly been studied in solution, ${ }^{[12]}$ and despite the fact that ball milling strategies towards related products have extensively been utilized synthetically, ${ }^{[11,13]}$ mechanistic details of the mechanochemical pathway providing phenytoin (3) have never been investigated. Thus, focusing on the phenytoin synthesis here had two attractive features: First, it was hoped that a concise analysis of the mechanochemical reaction path by continuous insitu methods would allow identifying intermediates and byproducts known to reduce the yield of the final product. Second, and more general, we aimed at demonstrating the applicability of mechanochemistry to access industrially relevant products. ${ }^{[14]}$

In 1908, Heinrich Biltz reported the first synthesis of phenytoin (3) by heating an ethanolic alkaline solution of benzil (1) and urea (2). ${ }^{[15]}$ Ever since, studies in solution have demonstrated the 
importance of the reaction stoichiometry to favor the formation of phenytoin (3) over unwanted species such as the double condensation product 3a,6a-diphenylglycoluril (4). ${ }^{[12 a]}$ Therefore, our first task in investigating the mechanochemical route to phenytoin (3) consisted in establishing the optimal stoichiometric ratio for benzil (1) and urea (2) under solventless ball milling conditions (Figure 1a). For these experiments the amount of $\mathrm{KOH}$ was set to two equivalents based on our previous studies. ${ }^{[8]}$ The results of this screening revealed that high conversion towards phenytoin (3) could be achieved by reacting equimolar amounts of benzil (1) and urea (2), while the amount of byproduct 4 was kept low even in milling experiments using an excess of urea (Figure 1a). Other bases such as $\mathrm{NaOH}, \mathrm{KOtBu}$ and $\mathrm{NaOEt}$ were also found effective for the reaction (Figure 1b). However, the highest yield of phenytoin (3) was obtained with $\mathrm{KOH}(73 \%$ after column chromatography).

After identifying the experimental conditions to obtain phenytoin (3), its formation during the ball milling process was studied. For this, real-time monitoring of the mechanochemical reaction between benzil (1), urea (2), and $\mathrm{KOH}$ was carried out by in-situ Raman spectroscopy in transparent poly(methyl)methacrylate (PMMA) milling jars. ${ }^{[16]}$ In an initial monitoring experiment, an equimolar mixture of $\mathbf{1}, \mathbf{2}$, and $\mathrm{KOH}$ (2.0 equiv.) was milled at 30 $\mathrm{Hz}$. In the first 5 min of milling, we observed a steady reduction in the intensity of several bands of 1 until the sudden loss of the Raman signal after ca. 5.5 min into milling (Figure 2a and Figures S1-S3). The loss of spectral information was due to rheological changes of the reaction mixture, which led to its compaction and sticking to the inner side wall of the milling jar, preventing proper mixing and grinding. After another 4 min of milling, the reaction mixture became a free-flowing powder again, and Raman spectra indicated the formation of the potassium salt of phenytoin $3-\mathrm{K}$ (Figure 2a and Figures S1-S3). A detailed analysis of the Raman data revealed that, prior to the rheological changes in the reaction mixture, a new transient band that belongs to an intermediate phase was formed at around $1300 \mathrm{~cm}^{-1}$. The appearance of this new signal was accompanied by a slight, but nevertheless distinctive, shift of the $\mathrm{C}-\mathrm{C}$ stretching band of the phenyl rings ${ }^{[17]}$ of benzil (1) at $1594 \mathrm{~cm}^{-1}$ towards $1598 \mathrm{~cm}^{-1}$, in combination with the disappearance of other benzil bands (Figure 2a and Figures S1-S3).

The generally accepted mechanism for the synthesis of phenytoin considers the intermediacy of potassium ureate $(\mathbf{A}),{ }^{[12 b]}$ a stronger nucleophile than urea (Scheme $2 a$ ). To rule out a direct reaction between benzil and urea or the formation of a cocrystal between
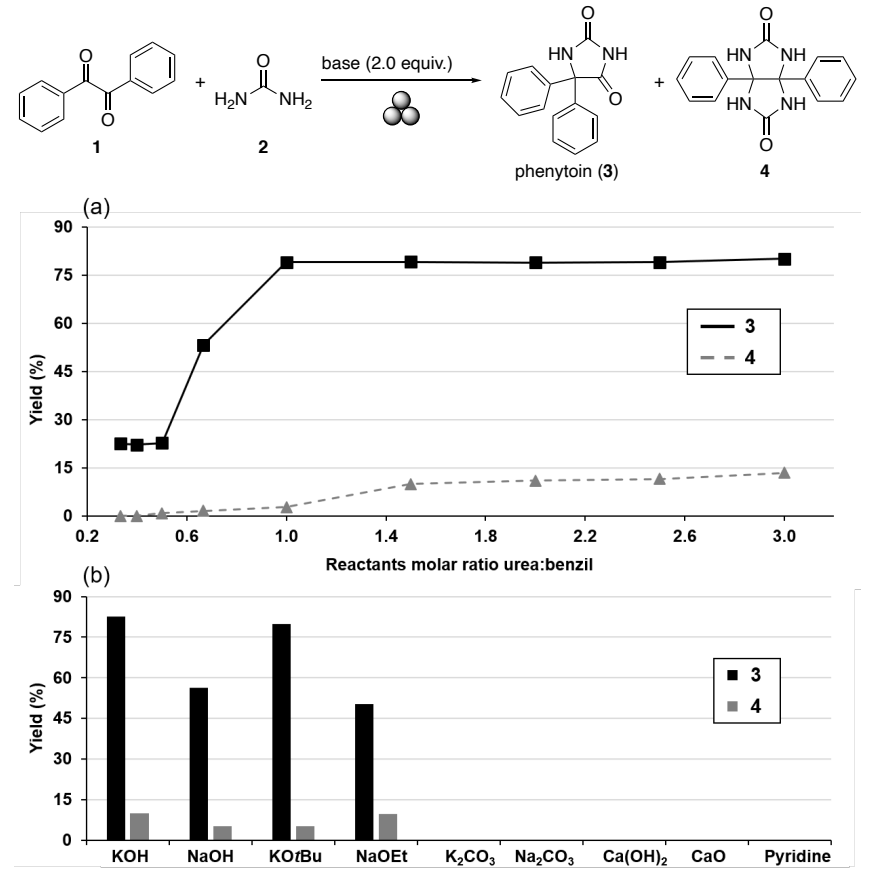

Figure 1. (a) Effect of the molar ratio of the reactants on the outcome of the reaction. Reaction conditions: $1(0.30-0.90 \mathrm{mmol}), 2(0.30-0.90 \mathrm{mmol})$ and $\mathrm{KOH}$ (2.0 equiv.) were milled at $30 \mathrm{~Hz}$ for $90 \mathrm{~min}$ in a $5 \mathrm{~mL}$ stainless steel milling jar with one stainless steel milling ball of $7 \mathrm{~mm}$ in diameter. (b) Effect of the base on the formation of 3 by milling $1(0.30 \mathrm{mmol})$ and $2(0.45 \mathrm{mmol})$ at $30 \mathrm{~Hz}$ for 90 min. In all experiments, $0.60 \mathrm{mmol}$ of the base was used except for $\mathrm{Ca}(\mathrm{OH})_{2}$ (0.30 mmol). Yields were determined by NMR spectroscopy using $1,3,5-$ trimethoxybenzene as internal standard.

them, we first carried out the grinding of $\mathbf{1}$ and $\mathbf{2}$ for $2 \mathrm{~h}$. Monitoring by Raman spectroscopy revealed only the physical mixture of the staring materials (Figure S4), thus demonstrating that under mechanochemical conditions, urea is not sufficiently nucleophilic on its own and that the presence of $\mathrm{KOH}$ is necessary to form the actual nucleophilic intermediate A. Consequently, the release of water in the formation of $\mathbf{A}$ could have led to the rheological changes observed in the reaction mixture. Indeed, when urea was milled only with $\mathrm{KOH}$, water droplets were observed on the milling jar wall while the reaction mixture fully stuck to one side of the milling jar wall. The use of milling-neutral auxiliaries in the reaction of 1,2 and $\mathrm{KOH}$ (sand, $\mathrm{KCl}$, neutral $\mathrm{Al}_{2} \mathrm{O}_{3}$ or $\mathrm{ZrO}_{2}$ ) could not prevent compacting and rheological changes of the reaction (a)

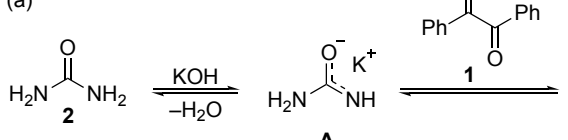

(b)
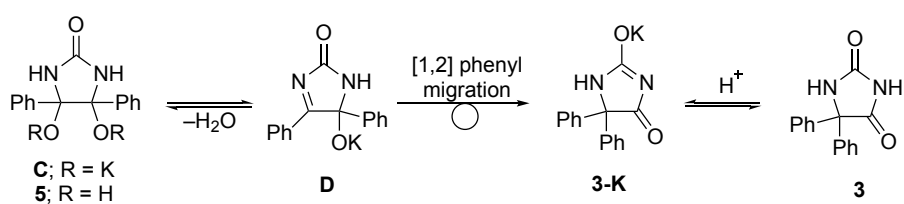

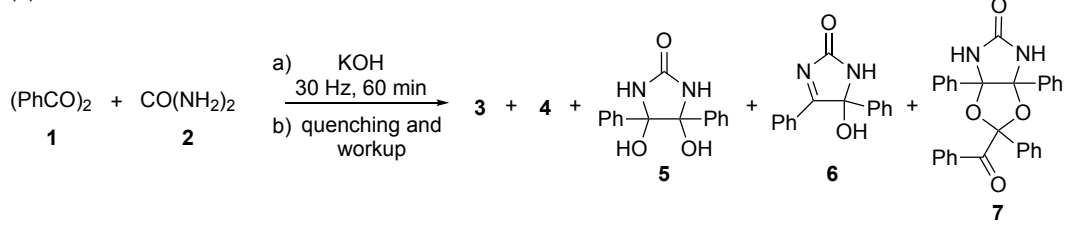

\begin{tabular}{|l|ccccc|}
\cline { 2 - 6 } \multicolumn{1}{c|}{} & $\mathbf{3}$ & $\mathbf{4}$ & $\mathbf{5}$ & $\mathbf{6}$ & $\mathbf{7}$ \\
\hline $\mathrm{KOH}(0.5$ equiv. $)$ & $1.1 \%$ & $2.2 \%$ & $22.3 \%$ & $0.0 \%$ & $3.4 \%$ \\
$\mathrm{KOH}(0.75$ equiv. $)$ & $4.8 \%$ & $2.0 \%$ & $31.5 \%$ & $1.6 \%$ & $0.0 \%$ \\
\hline
\end{tabular}

Scheme 2. (a) Plausible mechanism for the formation of phenytoin (3) by ball milling. (b) Product distribution of the reaction 1, 2 and $\mathrm{KOH}$ (0.5-0.75 equiv.). Yields were determined by NMR spectroscopy using 1,3,5-trimethoxybenzene as internal standard. 

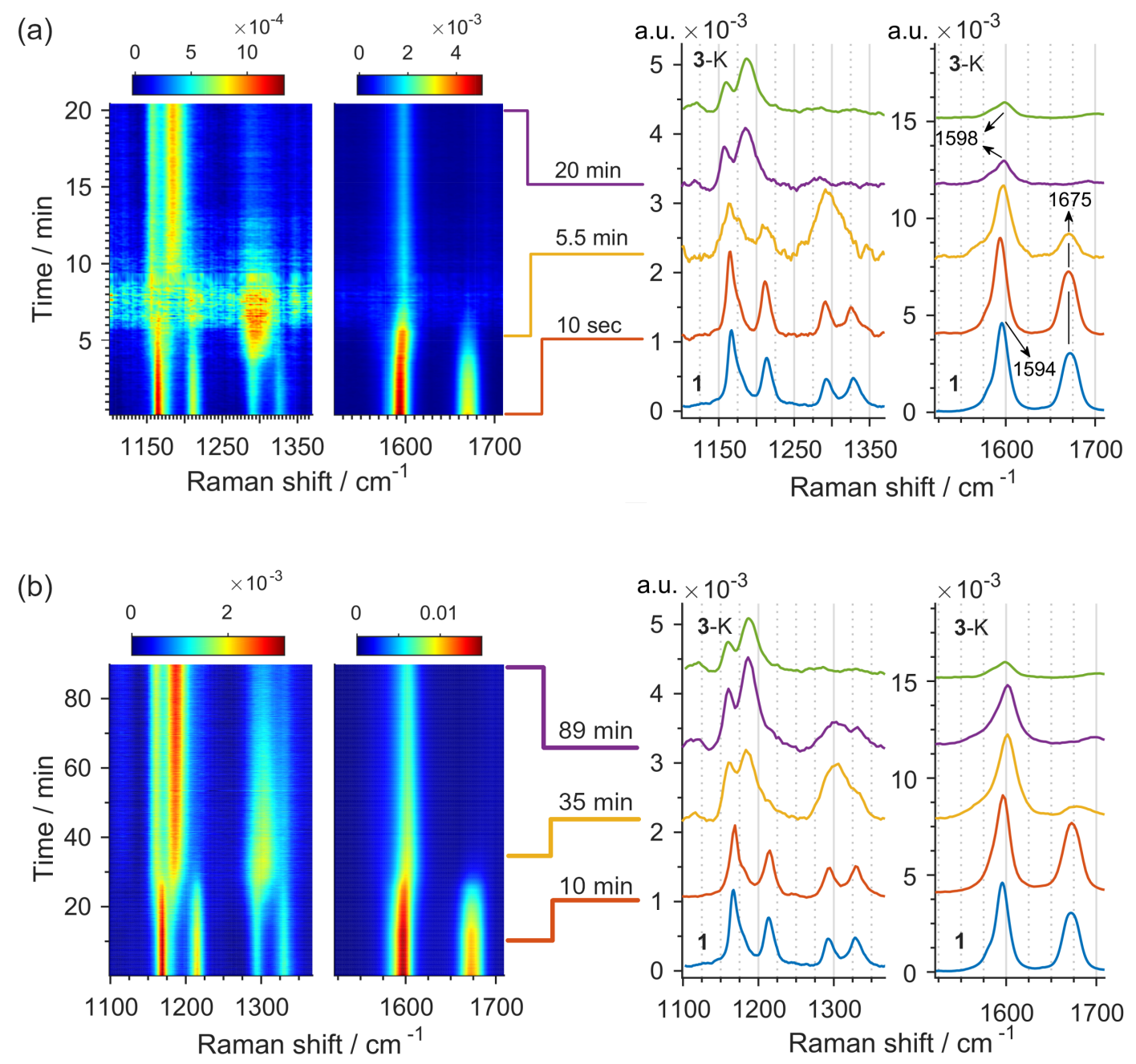

(c)
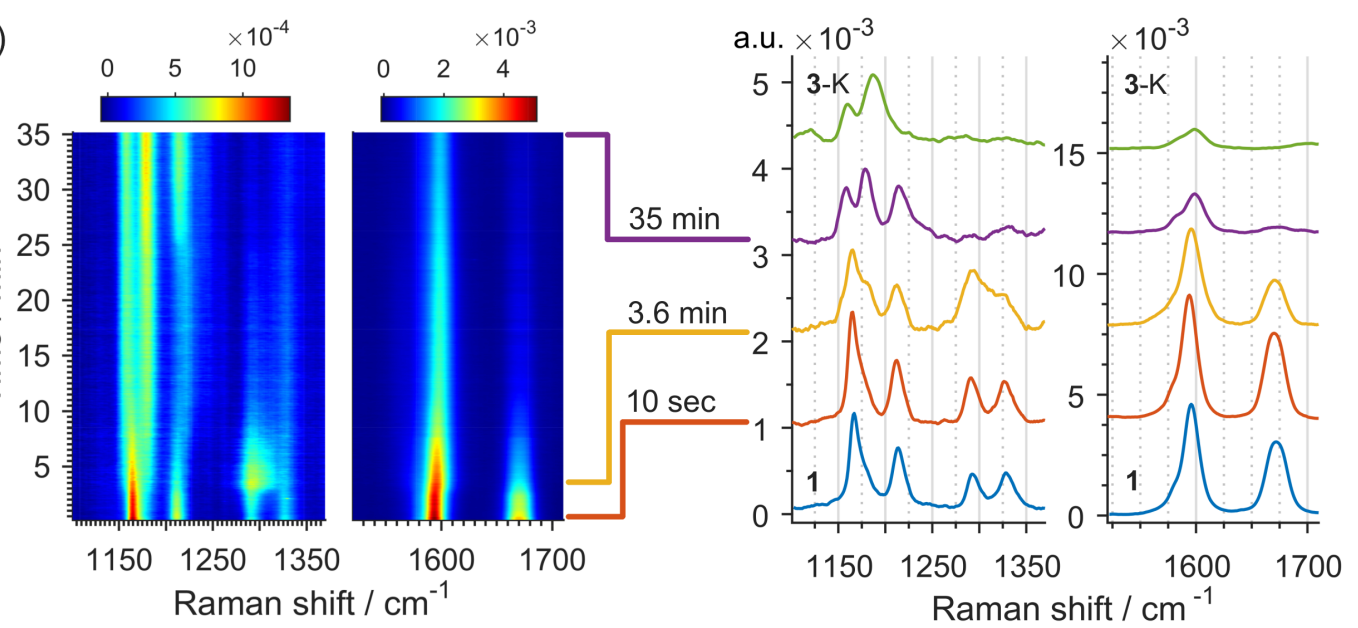

Figure 2. Time-resolved 2D plots of the mechanochemical milling at $30 \mathrm{~Hz}$ of: (a) benzil:urea: $\mathrm{KOH}$ in $1: 1: 2$ stoichiometric ratio and (right) Raman spectra of pure benzil ( 1 - blue) at the bottom and potassium phenytoin salt (3-K - dark green) at the top and selected spectra after 10 seconds, 5.5 min and 20 min of milling. (b) benzil:potassium ureate in 1:1 stoichiometric ratio (c) benzil:urea: $\mathrm{KOH}$ in 1:1:1 stoichiometric ratio.

mixture. However, formation of the phenytoin potassium salt $3-\mathrm{K}$ was still achieved. The inclusion of water (2.0 equiv.) to the initial reaction mixture of $\mathbf{1}, \mathbf{2}$ and $\mathrm{KOH}$ further favored the reactants' agglomeration inside the milling jar. However, after 10 min of milling, the reaction mixture again became powdery, and $\mathbf{3}$ could be isolated in $60 \%$ of yield. These milling experiments indicate that the initial changes in rheology of the reaction mixture (i.e., stickiness and compaction of the sample) are transitory and do not inhibit the formation of $\mathbf{3}$, which is achievable even in the presence of water.

Once potassium ureate $(\mathbf{A})$ is formed, it can act as a nucleophile towards one carbonyl group of $\mathbf{1}$, affording intermediate species 
such as B (Scheme 2a). From the continuous Raman monitoring of the reaction, we observed a correlation between the attenuation in the intensity of the band at $1675 \mathrm{~cm}^{-1}$, that corresponded to the $\mathrm{C}=\mathrm{O}$ stretching in benzil, and the appearance of a new band at $1300 \mathrm{~cm}^{-1}$ (Figure 2 and Figures S1-S3), ${ }^{[17]}$ which could correspond to the addition product $\mathbf{B}$ (Scheme 2a). Such a variation simultaneously proceeds with the previously described shift of the $\mathrm{C}-\mathrm{C}$ stretching band of the phenyl rings (Figure 2a). Next, potassium ureate $(\mathbf{A})^{[18]}$ was independently prepared and its reaction with benzil (1) in the absence of the $\mathrm{KOH}$ was monitored in-situ (Figure $2 b$ ). This experiment clearly showed the formation of the band at $1300 \mathrm{~cm}^{-1}$ and a gradual transformation to phenytoin during $90 \mathrm{~min}$, indicating the intermediacy of potassium ureate $(\mathbf{A})$ and $\mathbf{B}$ in the formation of phenytoin (3) by ball milling. This reaction could be accelerated in the presence of $\mathrm{KOH}(0.5$ equiv.) (Figure S5).

In the search to identify additional intermediates involved in the formation of $\mathbf{3}$, the reaction of $\mathbf{1}$ and $\mathbf{2}$ with smaller amounts of $\mathrm{KOH}$ (0.5-1.0 equiv.) was monitored. In the experiment using 1.0 equiv. of $\mathrm{KOH}$ the reaction mixture remained a free-flowing powder throughout the entire experiment, and the real-time Raman data revealed the formation of a new phase that did not correspond to the phenytoin potassium salt $3-\mathrm{K}$; similar results were obtained using 0.75 or 0.5 equiv. of $\mathrm{KOH}$. This new species had characteristic bands at $1214 \mathrm{~cm}^{-1}$ and $361 \mathrm{~cm}^{-1}$, and persisted unchanged over $120 \mathrm{~min}$ of milling (Figure 2c and Figure S6-S8). Motivated by the freedom to maneuver that the real-time monitoring provided us and thanks to the apparent stability of the newly detected phase, we attempted to isolate it. For this, 1, 2, and $\mathrm{KOH}$ ( 0.75 or 0.5 equiv.) were reacted for 60 $\mathrm{min}$ followed by the quenching of the reaction mixture. Analysis of the crude mixture by NMR spectroscopy showed unreacted starting materials and traces of $\mathbf{3}$ and $\mathbf{4}$. More importantly, diol $\mathbf{5}$ was detected as the major component of the mixture along with minor amounts of products 6 and 7 (Scheme 2b). We surmised here that both, diol 5 and imidazolone $\mathbf{6}$ reasonably relate to the corresponding intermediates $\mathbf{C}$ and $\mathbf{D}$. The identification of $\mathbf{5}$ and 6 was confirmed after their independent synthesis (for details, see the Supporting Information), while the ketal 7 was isolated from the mechanochemical reaction mixture. Independently, it was shown that 6 reacted with benzil and $\mathrm{KOH}$ providing 7. The observation and posterior isolation of the diol $\mathbf{5}$ and the imidazolone $\mathbf{6}$ is particularly relevant, as they correspond to intermediates originally proposed in the formation of phenytoin in solution, but whose isolation proved difficult (for 5 ) or not possible

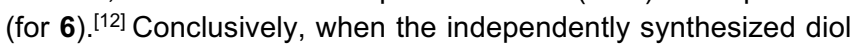
5 or 1,5-dihydro- $2 \mathrm{H}$-imidazol-2-one $\mathbf{6}$ were milled with $\mathrm{KOH}$, they readily rearranged into 3 , thus confirming their likely intermediacy in the reaction. The formation of $\mathbf{6}$ from the diol $\mathbf{5}$ was additionally corroborated by monitoring the spontaneous dehydration of $\mathbf{5}$ in solution by NMR spectroscopy (Figure S13). The observation of 6 in traces in the crude mixture (Scheme 2b) indicates that the phenytoin potassium salt $3-K$ could have formed via the intermediate $\mathbf{D}$, although the presence of $\mathbf{D}$ was not detected during the in-situ Raman monitoring. In fact, the formation of 3-K from diol 5 through the dehydration and the irreversible [1,2]intramolecular phenyl migration is expected to occur rapidly, as previously demonstrated for the analogous benzilic acid rearrangement. ${ }^{[8]}$
In summary, we performed a detailed mechanistic analysis of the mechanosynthesis of phenytoin, a WHO Essential Medicine. We clarified the importance of the stoichiometry of the reactants and the role of different bases ex-situ initially. Then, the application of in-situ Raman monitoring techniques enabled the unprecedented real-time insight into the mechanosynthetic pathway and allowed for the observation and isolation of elusive intermediates such as the diol 5 and imidazolone $\mathbf{6}$. These intermediates are also proposed for conventional synthesis but are hard or impossible to isolate from the solution. From a more general perspective, the depth of the reported investigation on the study of the mechanosynthesis of the phenytoin API undoubtedly creates an attractive opportunity for the propulsion of mechanosynthetic protocols among mainstream methodologies for synthesis.

\section{Acknowledgements}

C.B. and F.P. gratefully acknowledge the German Research Foundation (DFG; project BO 823/ 16-1) and the COST Action: CA18112-Mechanochemistry for Sustainable Industry (MechSustlnd) for financial support through a short-term scientific mission of F.P. This work is a contribution to the COST Action CA18112 supported by COST (European Cooperation on Science and Technology). We are also grateful to Dr. N. Biliškov and Dr. B. Karadeniz (Ruđer Bošković Institute) for technical assistance.

Keywords: Ball milling • in-situ monitoring • mechanochemistry • - phenytoin $\cdot$ rearrangements

\section{References:}

[1] K. J. Ardila-Fierro, J. G. Hernández, ChemSusChem 2021, 14, 21452162.

[2] For selected reviews on the application of mechanochemical methods in organic, inorganic, organometallic and nanoparticles chemistry, see: a) D. Tan, T. Friščić, Eur. J. Org. Chem. 2018, 18-33; b) J. L. Howard, Q. Cao, D. L. Browne, Chem. Sci. 2018, 9, 3080-3094; c) E. Boldyreva, Chem. Soc. Rev. 2013, 42, 7719-7738; d) A. P. Amrute, J. De Bellis, M. Felderhoff, F. Schüth, Chem. Eur. J. 2021, 27, 6819-6847; e) D. Tan, F. García, Chem. Soc. Rev. 2019, 48, 2274-2292; f) F. Effaty, X. Ottenwaelder, T. Friščić, Curr. Opin. Green Sustain. Chem. 2021, 32, 100524; g) T. Tsuzuki, Commun. Chem. 2021, 4, 143, DOI: 10.1038/s42004-021-00582-3; h) B. G. Fiss, A. J. Richard, G. Douglas, M. Kojic, T. Friščić, A. Moores, Chem. Soc. Rev. 2021, 50, 8279-8318.

[3] a) J.-L. Do, T. Friščić, ACS Cent. Sci. 2017, 3, 13-19; b) J. G. Hernández, C. Bolm, J. Org. Chem. 2017, 82, 4007-4019.

[4] a) C. F. Burmeister, A. Kwade, Chem. Soc. Rev. 2013, 42, 7660-7667; b) P. Baláž, M. Achimovičová, M. Baláž, P. Billik, A. Cherkezova-Zheleva, J. M. Criado, F. Delogu, E. Dutková, E. Gaffet, F. J. Gotor, R. Kumar, I. Mitov, T. Rojac, M. Senna, A. Streletskii, K. Wieczorek-Ciurowa, Chem. Soc. Rev. 2013, 42, 7571-7637. c) D. E. Crawford, C. K. G. Miskimmin, A. B. Albadarin, G. Walker, S. L. James, Green Chem. 2017, 19, 15071518; d) B. H. Bowser, S. L. Craig, Polym. Chem. 2018, 9, 3583-3593; e) R. T. O'Neill, R. Boulatov, O'Neill, R. Boulatov, R, Nat. Rev. Chem. 2021, 5, 148-167; f) S. Huo, P. Zhao, Z. Shi, M. Zou, X. Yang, E. Warszawik, M. Loznik, R. Göstl, A. Herrmann, Nat. Chem. 2021, 13, 131-139.

[5] H. Kohlmann, Eur. J. Inorg. Chem. 2019, 4174-4180.

[6] a) T. Friščić, I. Halasz, P. J. Beldon, A. M. Belenguer. F. Adams, S. A.J. Kimber, V. Honkimäki, R. E. Dinnebier, Nat. Chem. 2013, 5, 66-73; b) I. Halasz, S. A.J. Kimber, P. J. Beldon, A. M. Belenguer, F. Adams, V. Honkimäki, R. C. Nightingale, R. E. Dinnebier, T. Friščić, Nat. Protoc. 2013, 8, 1718-1729; c) D. Gracin, V. Štrukil, T. Friščić, I. Halasz, K. Užarević, Angew. Chem. 2014, 126, 6307-6311; Angew. Chem. Int. Ed. 
2014, 53, 6193-6197; d) L. Batzdorf, F. Fischer, M. Wilke, K.-J. Wenzel, F. Emmerling, Angew. Chem. 2015, 127, 1819-1822; Angew. Chem. Int Ed. 2015, 54, 1799-1802; e) K. Užarević, I. Halasz T. Friščić, J. Phys. Chem. Lett. 2015, 6, 4129-4140; f) S. Lukin, K. Užarević, I. Halasz, Nat. Protoc. 2021, 16, 3492-3521; g) G. I. Lampronti, A. A. L. Michalchuk, P. P. Mazzeo, A. M. Belenguer, J. K. M. Sanders, A. Bacchi, F. Emmerling Nat. Commun. DOI: 10.1038/s41467-021-26264-1.

[7] N. R. Rightmire, T. P. Hanusa, Dalton Trans. 2016, 45, 2352-2362.

[8] K. J. Ardila-Fierro, S. Lukin, M. Etter, K. Užarević, I. Halasz, C. Bolm, J. G. Hernández, Angew. Chem. 2020, 132, 13560-13564; Angew. Chem. Int. Ed. 2020, 59, 13458-13462.

[9] D. Virieux, F. Delogu, A. Porcheddu, F. García, E. Colacino, J. Org. Chem. 2021, 86, 13885-13894.

[10] World Health Organization Model List of Essential Medicines - 22nd List, World Health Organization, Geneva, 2021, pp. 5.

[11] For references of other biologically relevant hydantoin derivatives, see: a) M. Meusel, M. Gütschow, Org. Prep. Proced. Int. 2004, 36, 391-443 b) L. Konnert, F. Lamaty, J. Martinez, E. Colacino, Chem. Rev. 2017 117, 13757-13809.

[12] a) W. R. Dunnavant, L. J. Floyd, J. Am. Chem. Soc. 1956, 78, 2740 2743; b) A. R. Butler, E. Leitch, J. Chem. Soc., Perkin Trans. 21977 1972-1976; c) G. Schwenker, H. Guo, S. Bernhart, Arch. Pharm. (Weinheim) 1992, 325, 779-783.

[13] a) L. Konnert, B. Reneaud, R. M. de Figueiredo, J.-M. Campagne, F. Lamaty, J. Martinez, E. Colacino, J. Org. Chem. 2014, 79, 10132-10142 b) E. Colacino, A. Porcheddu, C. Charnay, F. Delogu, Reac. Chem. Eng 2019, 4, 1179-1188.

[14] a) J. G. Hernández, I. Halasz, D. E. Crawford, M. Krupička, M. Baláž, V. André, L. Vella-Zarb, A. Niidu, F. García, L. Maini, E. Colacino, Eur. J. Org. Chem. 2020, 8-9; b) I. Sović, S. Lukin, E. Meštrović, I. Halasz, A Porcheddu, F. Delogu, P. C. Ricci, F. Caron, T. Perilli, A. Dogan, E. Colacino, ACS Omega 2020, 5, 28663-28672; c) D. Tan, L. Loots, T. Friščić, Chem. Commun. 2016, 52, 7760-7781.

[15] H. Biltz, Chem. Ber. 1908, 41, 1379-1393.

[16] In our previous study (ref. 8) and in the present work the PMMA milling jars proved chemically stable to both the reactants and to the conditions for Raman monitoring. For a study on the photochemical stability of benzil in PMMA matrices, see: C. Kosa, I. Lukac, R. G. Weiss, Macromol. Chem. Phys. 1999, 200, 1080-1085.

[17] a) L. Colombo, D. Kirin, V. Volovsek, N. Lindsay, J. Sullivan, J. Durig, J. Phys. Chem. 1989, 93, 6290-6296; b) Ts. M. Kolev, I. N. Juchnovski, Spectrosc. Lett. 1993, 26, 1-16.

[18] J. Park, H. J. Kim, J. Korean Chem. Soc. 2016, 60, 251-256. 


\section{Entry for the Table of Contents}

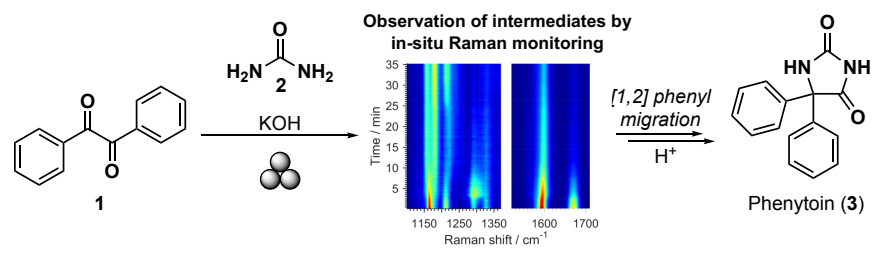

We report the in-situ monitoring by Raman spectroscopy of the mechanosynthesis of phenytoin, a World Health Organization Essential Medicine. This study enabled the observation, isolation and characterization of key molecular-migration intermediates involved in the transformation of benzil, urea, and $\mathrm{KOH}$ into phenytoin. 